\title{
Magnetic resonance imaging in ischemic heart disease: beyond structural analysis
}

\author{
Viktor Peršić*, Marko Boban, Vesna Pehar Pejčinović \\ Thalassotherapija Opatija, Opatija, Croatia
}

Diagnostic imaging in cardiology played an important role for continuous pace of improvements in basic knowledge and therapeutic guided decisions. ${ }^{1}$ Magnetic resonance imaging (MRI) has recently become a resourceful armamentarium in the field of every days clinical practice. Owing to technological developments, as increased power of magnetic fields, improved software for image acquisition and postprocessing offered significantly better image quality, while the timeline of examination was shortened. Inclusion of ECG and breath gated imaging offered further improvement in imaging quality by "freezing" of the beating heart in crucial important points for diagnostic analyzes. ${ }^{2}$ Combination of tissue characterization with functional imaging became increasingly important for clinical management of ischemic heart disea$\mathrm{se}^{3-5}$. Adenosine based vasodilatation joined with gadolinium contrast imaging is the most frequently applied pharmacological stress for assessment of ischemic heart disease. It is particularly resourceful for objectification of symptomatology and therapeutic decisions in cases with limited or non-diagnostic information obtained from conventional diagnostics. We present the most important issues in functional perfusion imaging and methodology for detecting the viable myocardium in order to attain more successful outcomes of revascularization treatments.

KEYWORDS: magnetic resonance imaging of the heart, myocardial stress perfusion, myocardial viability.

\author{
Received: $20^{\text {th }}$ Mar 2013 \\ *Address for correspondence: Thalassotherapija Opatija, Maršala Tita 188/1, \\ HR-51410 Opatija, Croatia. \\ Phone +385-51-202-724 \\ E-mail: viktor.persic@ ri.t-com.hr
}

\section{Literature}

1. Lima JA, Desai MY. Cardiovascular magnetic resonance imaging: current and emerging applications. J Am Coll Cardiol. 2004;44:1164-71.

2. Kramer CM, Barkhausen J, Flamm SD, Kim RJ, Nagel E; Society for Cardiovascular Magnetic Resonance Board of Trustees Task Force on Standardized Protocols. Standardized cardiovascular magnetic resonance imaging (CMR) protocols, society for cardiovascular magnetic resonance: board of trustees task force on standardized protocols. J Cardiovasc Magn Reson. 2008;10:35.

3. Kwong RY, Chan AK, Brown KA, Chan CW, Reynolds HG, Tsang S, et al. Impact of unrecognized myocardial scar detected by cardiac magnetic resonance imaging on eventfree survival in patients presenting with signs or symptoms of coronary artery disease. Circulation. 2006;113:2733-43.

4. Klem I, Heitner JF, Shah DJ, Sketch MH Jr, Behar V, Weinsaft J, et al. Improved detection of coronary artery disease by stress perfusion cardiovascular magnetic resonance with the use of delayed enhancement infarction imaging. J Am Coll Cardiol 2006,47:1630-8.

5. Rieber J, Huber A, Erhard I, Mueller S, Schweyer M, Koenig A, et al. Cardiac magnetic resonance perfusion imaging for the functional assessment of coronary artery disease: a comparison with coronary angiography and fractional flow reserve. Eur Heart J. 2006;27(12):1465-71. 